\title{
Coexistence of Systemic Lupus Erythematosus and Familial Mediterranean Fever
}

\author{
Gürsel Yildiz ${ }^{1}$, Mansur Kayataş ${ }^{1}$, Yasemin Uygun ${ }^{2}$, \\ Meryem Timuçin ${ }^{2}$ and Ferhan Candan ${ }^{1}$
}

\begin{abstract}
Clinical symptoms and findings of familial Mediterranean fever (FMF), occur as a result of autoimmune inflammation of the serous membrane which is also seen in systemic lupus erythematosus (SLE). Difficulties are sometimes encountered in the differential diagnosis of FMF because of similar clinical features with other autoimmune inflammatory diseases, and very rarely it can be seen with SLE. The association of FMF and SLE has been reported in one childhood case in Turkey. As far as we know, there is no report in the adult age group. Here, we present the first FMF and SLE association in an adult and discuss the pertinent literature in Turkey.
\end{abstract}

Key words: familial Mediterranean fever, systemic lupus erythematosus

(Inter Med 49: 767-769, 2010)

(DOI: 10.2169/internalmedicine.49.3102)

\section{Introduction}

Familial Mediterranean fever (FMF) is a disease of chronic autoimmune inflammation characterized by frequently relapsing fever and polyserositis; it particularly affects Jewish, Armenian, Arab and Turkish communities in the Mediterranean Sea region and shows autosomal recessive inheritance. The man to woman ratio is 1.5-2. FMF is thought to be due to a disorder in the configuration of the inflammatory response (1). Mutations have been determined in a gene called MEFV (MEditerranean FeVer) which is located in the short arm of chromosome 16 where two proteins involved in inflammation called Pyrin or marenostenin are also coded (2).

The etiology of systemic lupus erythematosus has not yet been fully understood. It is an autoimmune chronic inflammatory systemic disease which is characterized by antibody production against cell nucleus elements and causes tissue destruction. The woman to man ratio is 5/1. SLE is a disease of young women and it is seen in fertile age (3). Nonspecific symptoms such as weakness, fatigue, fever, loss of weight, and "poliserosit" (pleurisy, pericarditis, and peritoni- tis) are frequently seen. Butterfly rash, wide erythema, photosensitivity, discoid lesions, erythema nodosum, vasculitic lesions and Reynaud's phenomenon can also be seen. Symptoms related to musculoskeletal system, such as arthalgia, arthritis, myalgia, weakness, fibromyalgia are frequently seen. We found it worthy to present the present case because of the occurrence of these two rarely seen chronic diseases together and by the aim of reviewing the related literature.

\section{Case Report}

A 21-year-old woman consulted our polyclinic with symptoms of intermittent fever, abdominal pain, weakness in arms and legs, wide pain, and joint pains, which started 2 years-earlier. Considering the clinical symptoms, frequency of FMF in our area, and the existence of FMF in our patient's siblings, our client was evaluated for FMF. After determination of M694V mutation in FMF gene mutation analysis of the patient, she was diagnosed for FMF according to criteria developed by Livneh and colleagues for the diagnosis of FMF (4), $0.5 \mathrm{mg}$ colchicine p.o. three times daily treatment was started and the patient was followed. However, abdominal and joint pain did not improve and we

${ }^{1}$ Department of Nephrology, Faculty of Medicine, Cumhuriyet University, Sivas, Turkey and ${ }^{2}$ Department of İnternal Medicine, Faculty of Medicine, Cumhuriyet University, Sivas, Turkey

Received for publication November 2, 2009; Accepted for publication December 21, 2009

Correspondence to Dr. Gürsel Yildiz, drgursel@yahoo.com 
wanted to determine the etiology for the abdominal pain. Our patient had an operation for acute appendicitis. After the operation our patient terminated the colchicine treatment since there was no pain. But she reconsulted our polyclinic due to arm and leg pains from which she still suffered, and thus she was evaluated for other autoimmune diseases. On physical examination, her blood pressure was 100/60 mm $\mathrm{Hg}$ and pulse was $75 \mathrm{bpm}$. There were malar rash on her face and oral ulcers, photosensitivity. Cardiovascular and respiratory system and abdominal examination was normal. There was no lymphadenomegaly. Blood test values were: Hemoglobin 10.2 g/dL, hematocrite $30.5 \%$, leukocyte 7,000/ $\mathrm{mm}^{3}$, thrombocyte $304,000 / \mathrm{mm}^{3}$, CRP 5.9 and erythrocyte sedimentation rate (ESR) $91 \mathrm{~mm} /$ hour. Liver and kidney test values were normal: Uric acid $7.9 \mathrm{mg} / \mathrm{dL}$, albumin $3.7 \mathrm{mg}$ / dL, LDH: 287 U/L, CK: 35 U/L $(\mathrm{n}<192)$, aPTT: $54.3(\mathrm{~N}:$ 22-36), PT: 13, INR: 1.15. ANA $1 / 160(\mathrm{n}<1 / 40)$, Anti dsDNA was positive, anticardiolipin IgM was positive, anti ssDNA, PPD, anticardiolipin IgG, anti-histone, anti-Ro and anti-La antibodies were negative, $\mathrm{C} 3-\mathrm{C} 4$ values were found in normal value range. There was no specific finding in urine microscopy, and microalbuminuria in 24 hour urine was $56 \mathrm{mg} / \mathrm{dL}$. Abdominal USG was reported normal. Patient was diagnosed with SLE since five of the SLE criteria (malar rash, photosensitivity, oral ulcers, ANA 1/160 +, Antids-DNA and anticardiolipin antibody positivity) determined by American Rheumatology Association (ARA) were positive. Steroid therapy was started $(1 \mathrm{mg} / \mathrm{kg} / \mathrm{day})$ and arm, leg and joint pains were dramatically improved.

\section{Discussion}

SLE and FMF are chronic diseases with many common symptoms. FMF is characterized by limited fever and "polyserosit" (mostly peritonitis, arthritis, and pleuritis) and autosomal recessive inheritance. Gastrointestinal system involvement is seen in $20-40 \%$ of the patients and characterized by abdominal pain while possible causes may be peritoneal inflammation, vasculitis, pancreatitis, malabsorption, pseudo-obstruction or paralytic ileus. In addition, SLE patients with abdominal pain as the first symptom have been reported (5-7). While arthritis in FMF is mostly seen between attacks and it is localized in lower extremities as monoarthritis, in SLE it is mostly poliarthritis $(8,9)$. In some FMF subjects the prevalence of some inflammatory diseases such as Behçet's Disease, Crohn's Disease, seronegative spondyloarthropaties, Henoch-Schonlein Purpura, polyarthritis nodosa and elonged fibromyalgia is re- ported (10-14). In addition, it is reported that MEFV mutation may negatively affect the inflammatory prognosis of multiple sclerosis, Behçet's disease, juvenile idiopathic arthritis and rheumatoid arthritis $(13,15-18)$. On the other hand, there are studies reporting that the existence of FMF is protective over SLE. Based on this information the idea of high CRP values in FMF patients can be protective against SLE has been suggested (19). Determination of a definite relationship is possible only with evaluation of all FMF patients with ARA criteria for SLE diagnosis. Furthermore the probable incidence of SLE prevalence should be determined.

When the present patient was diagnosed with FMF, SLE was not considered due to the lack of at least four criteria of ARA and ANA was negative. However, ANA negative SLE is seen at a rate of $3-14 \%$. But, SLE had not been considered in our case because anti-Ro antibodies were negative.

SLE and FMF can be seen together (overlap) very rarely. There are 10 patients reported with both SLE and FMF (20-24). The present patient with homozygote M694V gene mutation and diagnosed with FMF, did not respond to colchicine treatment; she had an appendectomy and was diagnosed with SLE with malar rash, photosensitivity, oral ulcers, ANA 1/160 +, Anti ds-DNA and anticardiolipin antibody positivity when evaluated for other autoimmune diseases.

SLE may develop due to drugs including procainamide, hydralazine, quinidin and others with a low risk but druginduced SLE was not considered in the present case due to the fact that the anti-histone antibodies were negative. Also, she had not taken any other drug than colchicine and colchicine-induced SLE has not been reported in the literature.

In Turkey, to date the coexistence of SLE and FMF has not been reported in the adult age group. In a multi-centered study comprised of 3,000 FMF patients no SLE were found (25). However in the childhood age group Türkmen and Kavukcu (24) reported the coexistence of SLE and FMF in a 9-year-old girl. Thus, our patient is the first example of FMF and SLE coexistence in the adult age group.

In conclusion, with the similarity of clinical symptoms and findings, SLE and FMF which are two different multisystemic chronic inflammatory diseases can be seen together (overlap) in a patient. Probably the coexistence of these two entities is most likely a coincidence. In this situation, we think that patients with chronic inflammatory diseases who do not respond to treatment should be evaluated for other autoimmune diseases.

\section{References}

1. Kastner DL. FMF: The genetics of inflammation. Hosp Prac 33: 131-146, 1998.

2. Centola M, Wood G, Frucht DM. The gene for familial Mediterranean fever, MEFV, is expressed in early leukocyte development and is regulated in response to inflammatory mediators. Blood $\mathbf{9 5}$ :
3223-3231, 2000.

3. Gaubitz M. Epidemiology of connective tissue disorders. Rhematology (Oxford) 45(suppl.3): 3-4, 2006.

4. Livneh A, Langevitz $P$, Zemer D, et al. Criteria for the diagnosis of familial Mediterranean fever. Arthritis Rheum 40: 1879-1885, 
1997.

5. Sultan SM, Ioannou Y, Iseberg DA. A review of gastrointestinal manifestations of systemic lupus erytematosus. Rhematology (Oxford) 38: 917-932, 1999.

6. Chung HV, Ramji A, Davis JE, et al. Abdominal pain as the initial and sole clinical presenting feature of systemic lupus erythemetosus. Can J Gastroenterol 17: 111-113, 2003.

7. Benseler S, Silverman ED. Systemic lupus erythematosus. Rheum Dis Clin N Am 33: 471-498, 2007.

8. Lidar M, Kedem R, Mor A, Levartovsky D, Langevitz P, Livneh A. Arthritis as the sole episodic manifestation of familial Mediterranean fever. J Rheumatol 32: 859-862, 2005.

9. Cronin ME. Musculoskeletal manifestations of systemic lupus erythematosus. Rheum Dis Clin North Am 14: 99-116, 1988.

10. Fidder H, Chowers $Y$, Ackerman $Z$, et al. The familial Mediterranean fever gene as a modifier of Crohn's disease. Am J Gastroenterol 100: 338-343, 2005.

11. Balaban B, Yasar E, Ozgul A, Dincer K, Kalyon TA. Sacroiliitis in familial Mediterranean fever and seronegative spondyloarthropathy: importance of differential diagnosis. Rheumatol Int 25: 641-644, 2005.

12. Langevitz P, Livneh A, Zemer D, Shemer J, Pras M. Seronegative spondyloarthropathy in familial Mediterranean fever. Semin Arthritis Rheum 27: 67-72, 1997.

13. Schwartz T, Langevitz P, Zemer D, Gazit E, Pras M, Livneh A. Behçet's disease in familial Mediterranean fever: characterization of the association between the two diseases. Semin Arthritis Rheum 29: 286-295, 2000.

14. Langevitz P, Zemer D, Livneh A, Shemer J, Pras M. Protracted febrile myalgia in patients with familial Mediterranean fever. J Rheumatol 21: 1708-1709, 1994.

15. Rabinovich E, Livneh A, Langevitz $P$, et al. Severe disease in patients with rheumatoid arthritis carrying a mutation in the Mediter- ranean fever gene. Ann Rheum Dis 64: 1009-1014, 2005.

16. Rozenbaum M, Rosner I. Severe outcome of juvenile idiopathic arthritis (JIA) associated with familial Mediterranean fever (FMF). Clin Exp Rheumatol 22(4 Suppl 34): 75-78, 2004.

17. Atagündüz P, Ergun T, Direskeneli H. MEFV mutations are increased in Behçet's disease (BD) and are associated with vascular involvement. Clin Exp Rheumatol 21(4 Suppl 30): 35-37, 2003.

18. Shinar Y, Livneh A, Villa Y, et al. Common mutations in the familial Mediterranean fever gene associate with rapid progression to disability in non-Ashkenazi Jewish multiple sclerosis patients. Genes Immun 4: 197-203, 2003.

19. Özen $S$, Bakkaloğlu A. C reactive protein: protecting from lupus in familial Mediterranean fever. Ann Rheum Dis 64: 786-787, 2005.

20. Lidar M, Zandman-Goddard G, Shinar Y, Zaks N, Livneh A, Langevitz P. Systemic lupus erythematosus and familial Mediterranean fever: a possible negative association between the two disease entities - report of four cases and review of the literature. Lupus 17: 663-669, 2008.

21. Schreiber BE, Lachmann HJ, Mackworth-Young CG. Possible familial Mediterranean fever in a Caucasian patient with systemic lupus erythematosus. Lupus 17: 752-753, 2008.

22. Bakır F, Saaed B. Systemic lupus erythematosus and periodic peritonitis (FMF). Rheumatology 28: 81-82, 1989.

23. Langevitz P, Livneh A, Zemer D, Dolitzky M, Pras M. Systemic lupus erythematosus in patients with familial Mediterranean fever. Lupus 4: 11, 1995.

24. Türkmen MSA, Kavukcu S. Familial Mediterranean fever with atypical onset. Clin Exp Rheumatol 20: 100, 2002.

25. Tunca M, Akar S, Onen F, et al. Familial Mediterranean fever (FMF) in Turkey: results of a nationwide multicenter study. Medicine (Baltimore) 84: 1-11, 2005.

(C) 2010 The Japanese Society of Internal Medicine http://www.naika.or.jp/imindex.html 